\title{
15 ARGUING FOR INFORMATION SYSTEMS PROJECT DEFINITION
}

\author{
Mike Metcalfe \\ School of Accounting and Information Systems \\ University of South Australia \\ Adelaide \\ Australia \\ Maureen Lynch \\ School of Accounting and Information Systems \\ University of South Australia \\ Adelaide \\ Australia
}

\begin{abstract}
This paper is about project definition. The authors are concerned that the inquiry method, argumentation, is not fully appreciated with respect to how it can be used to critique attempts at the definition of projects. Therefore, and being upfront about it, this paper will argue that argumentation is useful for critiquing project definitions. The evidence presented in support of this argument includes definitions and descriptions of the attributes of both project definition and argumentation and then tries to formalize the way to apply argumentation to project definition drawing on recent experience by the authors with having to negotiate 14 six-month information systems (IS) project definitions with novice consultants. Space constraints permit us to elaborate upon only one of these. The implications of accepting the argument presented is to give more thought to this structured discourse approach to critiquing IS project definitions.
\end{abstract}

\section{INTRODUCTION}

Neal (1995) summarizes what many information systems (IS) managers know only too well: that, in recent years, the social and political pressures on 
new projects have increased considerably. Rapid changes in technology, new employment legislation, the power of unions, environmental pressures, and increased use of collaborative financing arrangements have changed the way projects are defined. New approaches are required that integrate these pressures with technical specifications. Neal goes on to argue that outcomes are becoming hard to set, so the project manager has to become a continuous planner through the life of the project. The approach of negotiating a fixed up-front contract with a single client may be too simplistic. Project definition may need to be less about the control of finances and more about the control of innovation or the control of learning-from-action. Neal continues that the client has become plural; co-client(s) who quarrel with each other and change their membership, who have very different and ever changing visions of the future. The successful project manager may well be the one who delivers what the stakeholder mix wanted at the end of the project, not what they asked for at the start.

This paper will address this problem of project definition, where project definition is defined as the process between appreciating that a new system is required and evolving a strategic design purpose to the stakeholders' satisfaction. In IS, project definition is about concept development or socially constructing the scope of the requirement analysis. The authors are concerned that many projects are ill-defined at the outset due to the lack of a good critical inquiry communications protocol, one that provides the correct degree of flexibility in the boundary. The critiquing protocol we suggest is the oldest and most common: reasoned argumentation between the stakeholders, including the designers. Argument works well as a way of critiquing attempts at project definition because it is a linguistic inquiry method that strives for clarity of definition, audience, boundary to the problem domain, constructive dialectic, separation of the object of study from the perceptions of it, and dynamics between stakeholders, and so it is (and long has been) ideal for the social construction of new concepts.

The evidence that will be presented in this paper is mostly experiential, that is, personal perceptions developed by reflecting on an action in the American pragmatist tradition brought into the IS literature (Argyris and Schön 1996; Churchman 1971; Weick 1983). Moreover, we agree with Haynes (2000) that Polanyi's (1966) concept of tacit knowledge is a vindication of experience evidence as long term doing alters people's perception of problems. The experiential evidence of others is sourced from written records, such as the IS literature, and from presentations by managers and academics at a small colloquium. Our own experience is based on many years of small research and consulting projects, but more specifically, for this paper, our experience of 14 six-month IS projects, one of which will be elaborated upon here. During these projects, the novice consultants responsible for completing the projects were 
specifically asked to test the idea of making explicit the argument inherent in their projects in order to see if it helped to gain client satisfaction from improved project definition. This experiential evidence will be used to support the argument that project definition benefits from being treated as an ongoing social argumentation process. The implications of accepting this argument are discussed but include having a simpler, more generic, more realistic project definition critique method rooted in the theory of knowledge philosophical literature.

\section{PROJECT DEFINITION}

That project definition is a very complex problem domain has been identified by numerous IS authors (Avison and Wood-Harper 1990; Checkland 2000; Davis 1992; Fitzgerald 1996; Mitroff and Linstone 1993; Settle-Murphy and Thorton 1999; Truex et al. 1999; Wastell 1996). Our understanding has moved a long way from Batiste and Jung's (1984) advice for good preimplementation briefings to executive staff. The more recent authors recognize the main problems as a lack of appreciation of powerful stakeholders, a failure to utilize the learning that will occur from the act of implementation, and having some way of distinguishing positive from negative project drift. Put another way, a systemic (holistic) approach is often not used, even by IS managers. These same authors point out that project definition is a difficult enough task with physical construction projects; with information and communications system (ICS) projects, it can be a particularly wicked problem (Checkland 2000; Roberts 2000; Pettigrew 1998). The extra problems include the need for numerous people to reschedule their daily work practices, and that the finished system really only amounts to a group of people with some networked communications that can easily be hijacked for purposes not intended by the designers. Moreover, clients are often only able to supply an initial brief that they want "something better" in the context of their company and an industry undergoing major changes, plus rapidly changing specifications on the relevant technology. The move to Web-based information systems and the development of powerful system-building software tools means that more and more ICS projects are being handled at the departmental level. This makes the enforcement of any professional body of knowledge for project definition even more difficult.

Readers familiar with the IS literature will already appreciate the massive waste caused by the failure of too many ICS projects. This failure is very obvious and well reported in both the academic and popular press (Mitev 2000). 
In New Zealand, there was a failure to get a new taxation system to operate. In Melbourne and London, there was a massive failure of the emergency ambulance callout systems. In France, there was a national outcry caused by the failure of the train ticketing system, Socrate. The list is nearly endless; indeed there is increasingly an expectation of large technical projects to go over budget or fail to deliver to expectation. As early as 1990, Angell (1990) warned that industry was becoming wary with the promise of IT. Improved performance on projects may be overdue.

Smith (2000) suggests definition improvement would result from using a series of interview appraisals either at the end or during the project. While this might gather some useful information, and knowledge that an appraisal will be done may focus stakeholders' attention, it may also give stakeholders the opportunity to disassociate from having to build ongoing working relationships with other project managers, objectify the problems and distance themselves from having to implement whatever is learned from the appraisals. Neal (1995) outlines how to use Checkland's $(1981,2000)$ soft systems methodology for project definition, but the methodology seems to have been designed around the problem of ill defined projects. Jayaratna (1994) outlines, in some detail, the limitations of the soft systems methodology, but the most obvious criticism is that, after three decades, it is still not widely used. It has become necessary to note that the principles on which soft systems are designed may make better design advice than its rather detailed method.

Project definition is normally thought of as something completed at the outset of a project (Kuhn 1970). While appreciating why writers say this, it can be a bit misleading in two ways. First, it may be wise to think of project definition as an ongoing process over the life of the project. The advice of Moynihan (2002) for as much "explicitness, clarity and formality" as does not stifle innovation at the start of a project seems reasonable enough, but project creep should be not be seen as an evil to be minimized, controlled and codified. Rather, it should be expected, planned for and seen as a result of having an organizational learning-from-action inquiry (Churchman 1971; Schön 1983) system operating effectively. Second, new projects come from old ones. Angell talks about realizing the disposition of the organization to birth and successfully nurturing a new system. Continuing with the evolution metaphor, the baby needs to be a feasible mutation of the parents. Project definition may be thought of as starting even prior to conception, birth being when the action (doing) starts.

Argyris' (1996) theory in action advises that any such project definition method needs to be pitched at the right rule of thumb level of analysis. If too abstract, like Von Bertalanffy's (1968) general system theory, or Ashby's law of requisite variety (Angell 1990), then departmental level practitioners will not 
use it. If too specific, then it may not be able to capture a whole perspective. The holistic methodologies driven from Churchman's design of human inquiry, Checkland's (1981, 2000) soft systems, and Mitroff and Linstone's (1993) multiple perspectives, including argumentation, are intended to be pitched at an appropriate pragmatic level. However, while the Churchman-derived methodologies have improved the quality of ICS project methodologies, it has become clear in more recent times that there is now even more need to focus on the upfront project definition stage (Fitzgerald 2000; Russo 2000).

Part of the problem with project definition has been a failure to appreciate the political power of all of the stakeholders in a project-from consultants to competitors. The time to capture the rampant forces of powerful stakeholders appears to be during the project definition stage. Project failure is believed to start with a failure to identify and describe fully and clearly the problem domain subject to a new system. Put another way, project suggestions need to be subjected to a formalized process of critique. Settle (1971) argues that organizationally applied critique is the key. Ulrich $(1983,2001)$, over 20 years, has been arguing for IS managers to develop critique heuristics to reveal underlying assumptions inherent in proposed projects. The bag of critique methods available for organizations to apply includes Morgan's metaphoric analysis (1986), and Marx and Engles dialectic forces (Sowell 1985), but the central method of critique is argumentation.

\section{ARGUMENTATION}

Objectivity results from the heated, intense, and biased confrontation and struggle between the somewhat biased ideas of somewhat biased individuals. That which survives the process is labeled objective (Mitroff 1972).

The dialectic (reasoned) argumentative process (debate, not quarrel) is about the only nonviolent mechanism humans have to construct, refine, apply, or challenge new concepts. People who claim to have a new idea or perspective are asked to justify their claims by providing supporting evidence while others are allocated the competitive task of thinking of ways to counter this evidence. Structures for organizational argumentation have developed over the centuries especially within the justice system. This process of organizational argumentation already occurs between project managers. This paper is merely trying the make the process explicit and apply it to the context of project definition. 
That projects inherently contain an argument or compromise tension has been long acknowledged in the IS literature (Churchman 1971; Mason 1969; Mitroff 1972; Mitroff and Linstone 1993). For example, the design of the building you are in can be viewed as the end result of an organizational argumentation between cost and functionality. Project definition as an argumentation approach aligns with what Crosswhite (1996) and Walton (1998) call persuasive dialogue reasoning; that is, it assumes you are trying to convince cynical, yet competent, opponents of your claim or, in the case of a project definition, of your scope and requirements. The philosophical basis comes from the dialectic reasoning of Socrates, Plato, and Aristotle, revisited through Eemeren et al. (1987), Perelman and Olbretchts-Tyteca (1969), Toulmin (1964), and Walton (1998), and through Habermas (see Ulrich 2001), the guarantor of a good outcome being fair rules of verbal competition between the stakeholders and the designers.

As mentioned above, project definition is seen as making an idea explicit in a group setting. It is the construction of a shared situation definition between the new system's stakeholders. As a workable method of achieving this, argumentation as an up-front critique methodology is being suggested, the process being that one of the stakeholder groups puts forward a design suggestion and the other stakeholders go through a process of critiquing it to reveal the underlying assumption in the suggestion. This contrasts with Mason and Mitroff's (1981) suggestion that two drafts should be encouraged at the outset and a comparison used to draw out a synthesis plan. Mao's arguments can be used to support the critique one idea at a time approach as he points out that, in any argument, there is always a dominant side which the weaker side has to attempt to overcome. This, plus the point that the resources required for two plans to be drafted may be unacceptable, makes us suggest this critique approach.

Hirschheim et al. (1997) advise that a desirable attribute of an IS methodology is "to provide a learning methodology to support debate on desirable and feasible changes." This aligns with Aristotle's (in rhetoric and topics) understanding of dialectic argument and Socrates' (through Plato) calls for knowledge claims to be questioned. Over the centuries, these two sources have been accepted by two epistemologies, science (Popper 1971) and interpretivism (Churchman 1971). Scientists see argument as a device for discovering the one truth, while interpretivists see it as a tool for justifying and explaining a perspective. While argument is not a decision-making technique that suits all problem situations, regardless of the epistemology used, large, complex IS project definition passes as wicked and therefore is an application for the argumentation approach. 
The epistemological issue also raises the issue of consensus. The scientific view, and some versions of the interpretive view, assumes that the agenda is to gain consensus, the first by proving the truth, the second by calling for consideration to be given to the views of all stakeholders and a negotiated consensus agreed. The purpose of consensus is to assist with the integration of the technical, organizational, personal, and social aspects of a project. This may be a little naïve. It does not address the practicalities of dealing with equal-power stakeholders, as witnessed by the violent history of the earth. Professional negotiators and political realists point out (Provis 1996) that all that can be hoped for is a resigned acceptance of a decision process. Argumentation, with each side providing evidence to support their position and a hopefully impartial third party making the decision, is a very common solution.

The argumentative approach is being used at present, albeit informally, in practice. If Scult (1999) is correct, people cannot help but argue because the use of persuasive language in any group interaction is an ontology, ${ }^{1}$ a way of being. This paper merely provides a metaphoric label to make the method more explicit, a philosophical base for why the method should be given more attention, and a more formalized modus.

\subsection{Inquiry and Decision Making}

What exactly is the argument method, and how does it overcome some of the problems inherent in effective project definition? First, what is a reasoned argument? Argument is the noun of arguing, the directed construction of convincing evidence (Perelman and Olbrechts-Tyteca 1969). Eemeren et al. (1987) define arguing as a social, intellectual, verbal (spoken or written) activity serving to justify or refute an opinion (idea, conception, policy), consisting of a constellation of statements and directed toward obtaining the approbation of an audience, the argument being the one line claim (conclusion) that is supported by various evidence. The courtroom analogy has been mentioned. Court protocol has also been designed around the open public forum approach suggested by Aristotle. A court case is a research activity; the courts are also searching for knowledge, indeed, the truth. Evidence is presented to a universal audience (jury) sufficient to convince them. In a court room, the argument is typically about a person's guilt. In IS definition, the argument is more likely to be something like "system design X is preferable." It is not possible to say what will be sufficient to convince the audience. That will depend on the issue and

${ }^{1}$ Scult (1999) argues that Heidegger thought rhetoric should be thought of as an ontology, since (as) group rhetorical interaction is a basic action of being. 
the audience. Apotheloz et al. (1993) summarize this point by saying that an argument is accepted only if the reasons it provides seem "plausible, relevant, oriented in favor of the conclusion, and sufficient to support it."

Eemeren et al. go on to explain their definition. They start by pointing out that arguments are a social activity because two people need to be present, holding two different worldviews. This is very relevant here because the argument approach, the dialectic, is about designing dialogue rules that allow the gaining of knowledge using differing views, while avoiding hostile conflict. So argument is an intellectual activity, an activity of reason, where emotion is channeled into reason. Eemeren et al. contrast this with the alternatives of letting truth be defined as the thoughts of the powerful, or in adopting a guru model where a few intellectuals are considered the fountain of all clever insights. The cornerstone of the courtroom system is that it should remove all of the power issues and allow all perspectives a voice. So, the act of professional arguing aligns itself with the accepted ethos of scientific decision making, critical thinking.

Eemeren et al. agree:

Argu[ing] always refers to a particular subject concerning which opinions can and do differ...all scientific, scholarly, areas of human knowledge...without any exception whatever, may be the subject of argument. Yet, argu[ing] requires the use of language....Argu[ing] is offering, defending against, taking account of, and anticipating criticism. Argu[ing] consists of a constellation of one or more statements....The common feature to both pro arguments and contra arguments is that both forms are directed towards testing the opinion.

Ziegelmueller and Dause (1975) make this connection between argument and inquiry directly: "Research skills stand at the very heart of the inquiry phase of argu[ing]."

Both in the sense of providing good information for making decisions and for assisting with the act of actually making the decisions, setting up a wellmanaged process of argumentation research appears to have a philosophical basis, and is integrated with the inquiry epistemologies.

Even in the very empirical psychology literature, the role of reasoned argument for the very tasks confronting an IS systems designer is supported. Tracy and Glidden-Tracey (1999) propose three elements that are related to conducting research as a reasoned argument: "(a) focus on underlying assumptions, (b) avoidance of compartmentalizations of research components, and (c) iterative comparisons of assumptions across components." This empha- 
sis on revealing underlying assumptions is an integral part of argumentation and something that makes this approach particularly relevant to project definition. Urlich (1983) refers to it as boundary judgements.

Tracy and Glidden-Tracey go on to say that to argue before a critical audience for a specific approach from among identifiable options requires careful thought and more careful articulation of assumptions. This aligns with the extensive management literature on the use of argument in both problem formulation and decision making. For example, Niederman and DeSanctis (1995) report that the argument approach leads to a greater combination of both coverage of critical issues and higher satisfaction with the problem definition exercise, leading to a greater commitment to implementation.

Meyers and Seibold (1989) provide an extensive review of the use of argument in this decision making literature, concluding that researchers have studied whether utilizing an argumentative methodology contributes to higher quality decisions and the results are that it is both useful for surfacing assumptions and evaluating crucial information in uncertain and ill-structured decisionmaking situations, which sounds very much like project definition.

They go on to say that arguments are both the medium and outcome of group interaction. Well managed, it is a group social practice, which is why it works so well for negotiations between powerful stakeholders. Arguments are both a system (observed patterns of interaction) and a structure (the unobservable generative rules and resources that enable argument). This links into the structuration perspective derived from Giddens' (1984) theory, with culturally appropriate and sanctioned ways of disputing. Meyers and Seibold align their argument with Giddens' theory, saying that argument provides the interaction system (in Giddens' sense) needed to make a structure. In this paper, this is applied, saying that argument can also be used to improve and solidify first thoughts on project definition. The managerial task is to manage this argumentative process so that individual managers' private agendas, emotions, and power needs are held in perspective, while allowing innovation and reflection (Schön 1983).

Myers and Seibold also summarize the extensive empirical research on analyzing argumentative processes. This is aimed at observing how a determination was made. To date, much of this research has been done using the positivist laboratory methods such as quantifying different types of individual and group interactions and then trying to extrapolate the outcome. This research approach is not thought to provide rich enough insights to inform practicing managers, partly because all parties would be aware of the research findings. However, Fischer and Forrester (1993) report on more interpretive research being undertaken on the role of argument in government policy formulation. They 
again report that it was very helpful in drawing out issues and in improving understanding between parties.

Decisions need to be communicated; the argumentation approach doubles up in this role. Users are more likely to be committed to a new design if they have been involved in a reasonable argumentative process or if their questions are anticipated by reporting the arguments or evidence. If nothing else, the perceptions of the purpose and context of the new system will be better communicated. The management literature supporting the role of argument to assist communication is even more extensive than the decision-making literature. Meyers and Seibold summarize it by saying that, from the discipline's beginnings in the late nineteenth century as forensics pedagogy, the study of argument has been a rich intellectual tradition in the field of communication.

A further attraction of the argument approach is that it makes bias explicit. Pretending to be impartial where repeat experiments were not possible has caused a lot of stress in scientific inquiry (Broad and Wane 1982) and is unconvincing in the political competition of modern organizational life. Much time and emotion is saved if each actor openly states his or her preference or claim up-front rather than pretending to present impartial questions, and then is asked to justify this claim in a public arena.

\subsection{Argument for Project Definition}

Numerous writers on project definition (e.g., Checkland 2000; Darke and Shanks 1997; Mitroff and Linstone 1993) emphasize the need for ongoing appreciation (Vickers 1984) of stakeholders' viewpoints on the project. Darke and Shanks list 15 possible techniques for understanding and representing viewpoints, but they observe, with some concern, that within their case studies very little time was actually spent on aligning viewpoints. The core point of the argumentation method, while being more in the form a conceptual frame than these 15 techniques, is to allow stakeholders to understand and justify their viewpoint. With five stakeholder views, it may be a five-way argument, but the intent is to insist that each group justify its view to the others who may or may not accept the justifications.

Metcalfe (2002a) outlines one possible procedure for providing a forum for these justifications to be made at an organizational level. It mirrors the court system with roles allocated to due process, enthusiastic counterargument, and a clear decision at the end. However, the application of the argument method to project definition presented here is designed around the earlier stage of stakeholders trying to develop, through critique, a vague project concept. Ulrich (2001) sees the primary role of critique as revealing underlying assumptions in 
the project concept by exploring the boundaries of the project sponsor's argument.

Application of the argument method to project definition starts by appreciating that every human endeavor, every humanly designed artefact, contains an implicit argument. An example would be that IS projects have an implicit argument that a particular design is the optimum one given the resource constraints. The definition exercise is one of interactively building up a design with the conflicting stakeholders and the resource constraints. The design and the criteria will be dynamic, each changing as ideas are added and explored. Providing any rules for managing this complex and creative interaction is hard. The only contribution that can be made is to suggest some protocol for the dialogue. This is what argument does.

\section{PERSPECTIVE THINKING}

The authors believe a very effective method for project definition emerges if the huge philosophical base for argument as an inquiry methodology is combined with another theory of knowledge thread that seems to have come out of Kant, Hegel, and Heiddegger. This was hinted at by Churchman (1971), developed into a management tool by Mitroff and Linstone (1993), elaborated upon by Linstone (1999), graphically captured by Checkland (2001) and linked back to its philosophical roots by Haynes (2000). Moreover, it also aligns with Kuhn's (1970) paradigms and the idea of theory-laden observation (Chalmers 1982). It is about separating the object under consideration from the perspective with which it is being viewed.

Morgan's (1986) metaphorical analysis of organizations is a classic example of this separation. The object under consideration was organizations; the perspective an analyst can have on this object is to look for organizations' machine-like qualities. Another perspective is to look at organizations' adaptive organism qualities. Linstone uses a different set of perspectives. He suggests that complex social situations, such as organizations looking to change, be perceived from three perspectives: the technical (any physical factors to be counted and measured), the organizational (interdepartmental and/or supply chain relationships that need to be negotiated), and the personal (considering the change through the eyes of individuals given their unique concerns).

Davidson (1984) has expressed some reservations about being able to make explicit our ways of seeing or conceptual frame as it is possible to get into an infinite regress of perspectives on perspectives. However, Checkland (1981, 2000) and Haynes (2000) have found the act of separating the object and the perspective very pragmatic, for understanding complex problems or, more specifically, project definition. 


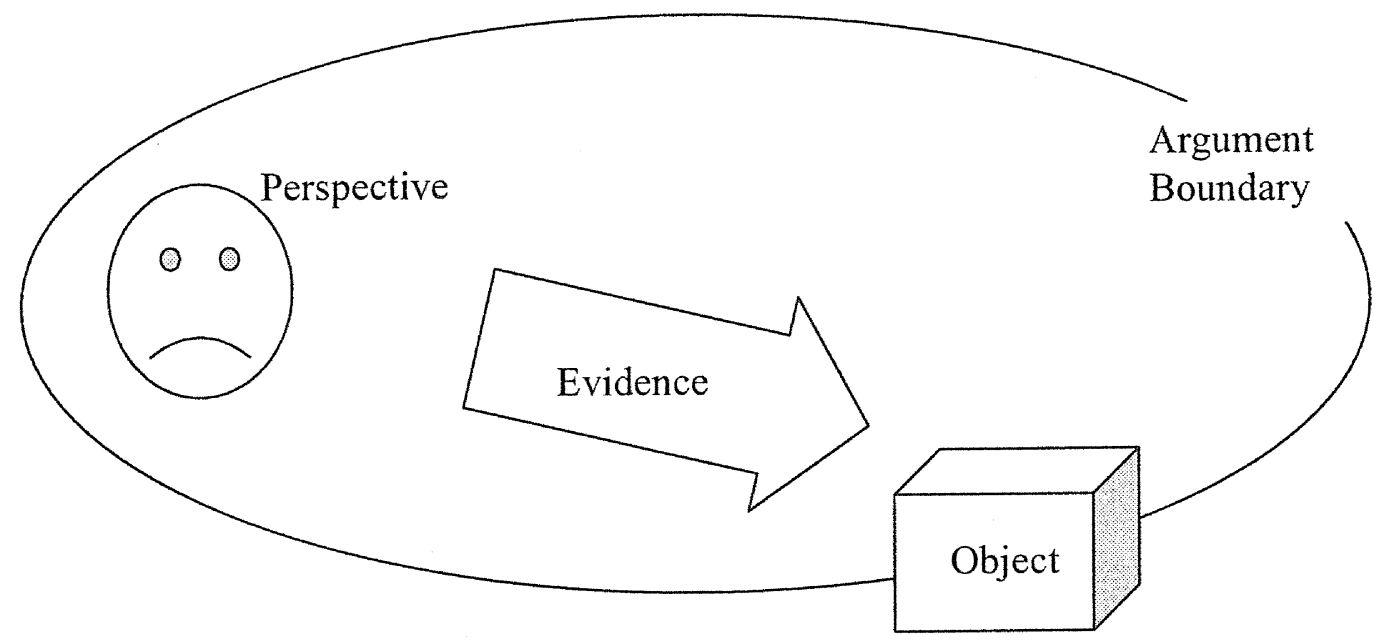

Figure 1. The Perspective/Object Separation

Checkland's (1981, 2000) FMA graph has been used by the authors to graphically explain perspective thinking's call for an explicit separation of the object from the perspective of the inquirer (see Figure 1). The perspective is upon an object; the arrow labeled evidence reminds that there needs to be some process or inquiry method where the perspective collects memories or evidence about the object. The perspective and the object can change independently. For example, if the perspective is technical expertise as power, the object could be a new system or the determination of a corporate strategy. Also, a new system could be perceived through a resources perspective. The dialectic is that when one does change, it has some effect on the other. So, power issues for a new system are different from those relevant to drafting a new corporate strategy.

\subsection{Applying Method to Practice}

This idea of separating the object from the perspective, which Haynes calls perspectival thinking, combines powerfully with the argumentation inquiry methodology. The argument sentence structure can be divided into two parts: the subject (or perspective) and the object. For example, in the argument that system $\mathrm{X}$ is the best one for company $\mathrm{Y}$, the object is company $\mathrm{Y}$ and the subject or perspective being taken on company $\mathrm{Y}$ is the usefulness of system $\mathrm{X}$. This is included in Figure 1 as the boundary ellipse. The ellipse surrounding the perspective/object separation is intended to be symbolic of these being contained within the argument. But the argument also acts as a boundary (Ulrich 2001) on the problem domain. Put another way, if a project (or a report) has a argument 
(conclusion), then this limits the project to what is and is not to be treated as relevant.

Over a number of years, Metcalfe (2002b) has found that, while it was useful to try to identify a manager's perspectives on a problem, there is some advantage in using the term concerns in day to day conversations. The question, "What concerns you about this?" is more quickly accepted in conversation than, "What is your perspective?" Maybe more importantly, asking for someone's concerns tends to encourage respondents not to over rationalize or theorize their perspective. Rather they can try to articulate a more personal, emotional, real perspective. Asking for someone's concerns also aligns with Keeney's (1994) and Churchman's (1971) advice that personal ethics and values provide people's most fundamental perspective on any activity in which they are involved. It is thought that asking for someone's concerns gives these values a voice. Using the term concerns also enables us to draw on Polaymi's (1996) work on tacit knowledge. Haynes interprets Polaymi to define tacit knowledge as having a different perspective of a problem due to experience. By asking for the concerns of experienced stakeholders, their tacit knowledge is being sought.

In the authors' experience with using the argument/perspectival thinking approach to project definition, the best place to start is with identifying the audience. This is fundamental to mounting a convincing argument. Assuming you are talking first to the main project sponsor, we have found the next best step is to try to identify the object, then the concern and then the argument. Typically, it works as follows: after some brief background discussion, the facilitator asks a series of questions starting with, "So what exactly is the object (or thing) under consideration?" Let's say the client's answer is, "Developing a corporate IT policy." That this is the object within the meaning of this approach can be confirmed by asking, "OK, so the report will contain a chapter on corporate IT policy." If the answer was, "Oh no, we won't need that sort of background material, we need to focus on controlling IT expenditure," then IT expenditure is the object.

The next question is, "What is it that concerns you about IT expenditure?" A possible answer could be, "How best to align IT expenditure with the overall corporate strategy." Remember that the point of using this language is to try to make contact with the core values or ethics of the stakeholders that are influencing their view of the world. So, in this case, the stakeholders appear to be calling for alignment that it is assumed to be a control need.

Of course, different stakeholders will have different concerns. Drawing these out might be assisted by using techniques such as structured rich pictures (East and Metcalfe 2002). However, it is assumed that the purpose of such exercises is not to seek consensus but rather to help the project owner appreciate the stakeholders' concerns. 
Having identified the object and project owner's concern, the next stage is to combine these two into the argument. Directly asking the client for their argument is usually inappropriate. Alternative language, if a report is involved, is to ask about the conclusions and recommendations. In this example, the conclusion might be that " $\mathrm{X}$ " is the best policy to ensure that IT expenditure is aligned with the overall strategy. This helps to identify the purpose of the report as being to provide the evidence to support this conclusion; it provides the boundary. The approach of starting with the format of the conclusion acknowledges that, ultimately, the project definition will need to be presented in a way that persuades others. It also brings together the object and concern in a purposeful manner. If the client is not clear about the direction of the conclusion, then it can be written in a neutral form. In this case, the format would be, "That the best policy is (is not) X." As evidence is collected and progress discussed with the client, the direction usually becomes clearer. Indeed, the whole format of the conclusion may change but it is believed to be important to start off by attempting to make the stakeholder's perspective explicit up front.

The a priori conclusion (argument) is simply an opening (a priori) position, and the inquiry process (action) is expected to alter the (posterior) argument (conclusion) as actions cause learning and new arguments emerge. Anything, and everything, from minor editing to a major redirection can be expected. Any empirics (experiences through the senses) or decision on what and how any inquiry is designed will be theory laden. It is believed that anybody undertaking an inquiry will have a concern acting to interpret his or her sensory inputs. Broad and Wane (1982) outline some of the problems that have flowed from scientists claiming to believe in their being unbiased or without prior conceptions during an inquiry. Up-front identification of the stakeholders' concerns or bias provides a more open contract with the audience.

\subsection{Inquiry Evidence}

Once the format of the a priori conclusion is established, it becomes easier to determine what evidence needs to be sought to justify the conclusion. This acts to reinforce what resources the stakeholders want invested in solving their concerns. The question, "What evidence needs to be collected to make the conclusion convincing?" needs to be asked. This question also clarifies which inquiry methods would be considered appropriate. Using the example, the method may be to seek a combination of experienced managers' opinions, comparative examples from other organizations, or a literature search for alternatives. This may be improved by proactively seeking diverse views. So, if one experienced manager is interviewed and responds by saying method $\mathrm{Z}$ is best, then tactful questioning should be used to elicit the name of someone else 
who would have a totally different opinion. Again, if it is a third party who gather the evidence, there is a risk that they will refocus their opinions of what the object being studied should be and what the concerns should be, so great care has to be taken to keep the stakeholders involved in any change-of-direction thoughts.

In the field of social inquiry, much of the evidence presented to support an argument is in the form of definitions. Continuing with the example of " $\mathrm{X}$ is the best IT policy," then the object of IT policy and the concern of the best need to be defined. Taking a systemic perspective does this usefully. For example, IT policy can be discussed in system thinking terms such as its purpose, its boundary, its interaction with other systems, inputs and outputs, and learning. Best can be described in the same way. It is the output of using criteria to rate alternative IT policies. The selection of these criteria to determine which policy is best will need to be defined systemically.

\subsection{Outcomes Versus Concerms}

Much of the project management literature advocates focusing on desired outcomes. Vickers (1984) argues strongly against this. It is an attempt to objectify the problem. Outcomes may or may not be achieved; often they are redefined anyway. Gaining stakeholders' support that a project should be deemed successful is the definition of success. This support may be better achieved by focusing on satisfying the stakeholders' concerns rather than professed outcomes. Using Mitroff and Linstone's (1993) division of the knowing world into technical, organizational, and personal issues, taking a concerns perspective rather than an outcomes one moves the perspective from technical to personal. Moreover, the soft systems writers (e.g., Checkland 1981; Ulrich 1983) have long argued that the purpose was a preferable perspective to outcomes for much the same reason. At the project definition stage, in the turbulent world of IS projects, outcomes are notoriously hard to lock in. The system thinking first set the purpose approach treats the stakeholders as motivated and having the ongoing local knowledge, able to set and adapt some tentative outcomes as the situation develops. The concerns approach, therefore, aligns with the primary use of purpose, maybe even linking purpose with stakeholders' values.

\subsection{Pragmatics}

From all of the above perspectives, a project definition critique process can be distilled. This is presented as series of questions intended for use as a critique 
of attempts to define a project in an interactive, dynamic manner based in dialogue. These questions can be listed:

- ARGUERS: Who is defining the project (project owner)?

- OBJECT: What is the object or thing central to the project? Is it well scoped and defined?

- CONCERN: What is the project owner's concern (perspective) about this thing? Are these concerns well understood?

- ARGUMENT: What is the argument inherent in the project?

- EVIDENCE: What evidence will it take to convince the project owner that the argument is justified?

An illustration of these using these questions is presented.

\section{AN ILLUSTRATION}

This study used an argument/perspective inquiry methodology to guide evidence collection. The underlying principle of this inquiry methodology is to persuade a cynical and hostile audience. It is a methodology used in critical social theory, not in terms of the emancipation theme (Alvesson and Skoldberg 2000), but rather in its intent to persuade by justifying an insight. The researchers are persuaded of the advantages of using argumentation to define projects after 10 years of testing it on university postgraduate research projects. This paper was designed to tempt others to consider the approach.

Klein and Myers (1999) and Myers and Avison (2002) provide a useful checklist for interpretive research, which is the way argument is being used here, but do not mention argumentation. By interpretive it is meant respecting that there are multiple reasonable interpretations of the physical world (Chalmers 1982; Kuhn 1970). The interpretations sought were those of participants in a new way to define projects, this being done to inform the authors of the effectiveness of the method. The empirical exercise had elements of action research as outlined by Myers and Avison and by Baskerville and Wood-Harper (1996) in so much as there was intervention in suggesting new ways the object under study (project definition) was undertaken. There was a clear up-front frame (concern), the usefulness of argument theory, and reflection against this frame over the term of the inquiry was demonstrated by the change in language used with the participants. The inquiry was grounded in a particular object of study and some understandings emerged from discussions with participants. Some hermeneutics were also involved as project documents and interview comments were studied for their meaning. The meaning gleaned by the researchers was aligned with the meaning intended by the other participants, it 
being accepted that some social construction of meaning took place between those who made the comments and those who interpreted them.

Unlike the tradition of critical social theory (Alvesson and Skoldberg 2000), empirics were separately designed to add persuasion to the inquiries' findings. However, in line with critical social theory, the intent was not to provide precision measurements but to justify our insight and to use action to learn (Argyris and Schön 1996). It was somewhat ethnographic in that the researchers were studying something with which the participants had lived all of their working lives. However, the researchers did take a new idea to this cultural group to observe their reaction. The study also had an element of being a case study in that sampling was not used; rather, a single locale of the participants in an industry-university collaboration program bounded the study. Moreover, the empirical evidence was collected over 6 months and tried to take a holistic view of the problem rather than measuring variables and their relationships. So, rather than try to label these empirics as cross-sectional or longitudinal, it may be more meaningful to call it systemic.

Our evidence collection actions were motivated by two main histories. First, the first author had, for over a decade, been encouraging research graduates to define their theses using the argumentation approach (Metcalfe 1995; Metcalfe and Powell 2000). He had started to apply the same approach with some success to the definition of consulting reports. Meanwhile, the second author had been looking for ways to offer training in project definition and scoping to inexperienced consultants. It was agreed to try to use the argument approach using action learning through training workshops and visits to places of employment. A six-stage process was put in place.

1. A small conference was arranged to ask experienced practitioners, consultants, and academics to discuss the issue of project definition and scope shift. The message the new consultants received was that project definition was a dynamic, wicked problem for which the only assistance was good communication with all stakeholders.

2. A 1-hour workshop for 14 new consultants was arranged to present the object/concern/argument approach using examples based on the previous experiences of those present. The first draft scoping documents for their next projects were provided with a warning that they were ill defined so far. Questions about the relevance of the approach to particular projects such as software coding were discussed.

3. After receipt of signed off scoping documents, workplace visits were arranged with the new consultants and their project managers. The protocol used was for the researchers to run through the object/concern/argument/ 
evidence questioning routine with the novice consultant, while the project manager listened in, making clarifications thought to be appropriate. An independent observer was shown the scoping documents and asked to observe the workplace questioning session. Afterward, the observer commented that she had gained considerable clarity from the questioning session. Some new consultants also thanked us for clarifying some details on either the project or scope. With one exception, the project managers agreed the scope had changed during the project. This one was adamant he would not allow change although he acknowledged that he would have scoped it differently given what he learned from undertaking the project.

4. A table was drafted that listed the object/concern/argument/evidence by project. This was supplied to each novice consultant. While editing was suggested, no one suggested that the table was misleading. Drafting the table did clarify that, while an argument was identified for each project, for some it was implicit in the system design. For example, if some code was required then the argument was that it was functional.

5. A second group workshop was arranged where three experienced practitioners, the two researchers and the 14 novice consultants discussed their experiences with project definition. First, time was taken to demonstrate how everybody uses their personal values to interpret ill-defined situations using the spare picturing method (Hospers 1982). Next, a list of issues compiled from the experiences recorded in the new consultants' journals was used to give some structure to a more general debate about project definition. Interestingly, one emergent issue was that, while the constant generic advice was for good communication, many stakeholders in the projects were unwilling or unable to be available for discussion.

6. At the end of the projects, each novice consultant was asked to give a presentation explaining the project and its outcomes to an audience comprised of the project managers and the researchers. While many consultants reported scope changes, there were no reports of conflict with the project manager.

7. Comments about whether the project managers got what they asked for by the end of the project were sought. During this exercise no feedback was received that there was a problem with project definition.

Below are some of the details on one of the 14 projects. Of course, alone it cannot be said to prove anything. It is presented in the spirit of showing an 
example of the questioning process that has been developed by the authors to apply the argument/perspective to project definition.

A problem with intervention style inquiry is that improvements in project definition may have occurred simply because of the Hawthorne effect, that is, because the topic of project definition was made a topic of conversation with the participants. This is thought to be a very valid point. It is most likely true for any organisationally based research where realistic in-context research is sought. Kummerow (2001) found this to be particularly true with researching corporate culture variables. In this case, a saving feature may be that the participants would have had experience of numerous other project management methods and a very acute appreciation of the pragmatics of their work situation.

Following is an edited copy of the project brief as provided to the novice consultant by the project owner (ARGUER). The original document was 880 words but space does not permit it all being reproduced. This is unfortunate as part of the message here is how the object and concern can get buried under other information. The scope and aims have been removed.

\section{Functional Requirements and Design Specifications for a Whole-of-Portolio Service Directory.}

\section{Project Outcomes}

The major outcome from this project would be improved service delivery through more informed decision-making regarding the strategic planning and operational management of service delivery processes. To successfully deliver high-quality, timely, and responsive services, the user's requirements must be mapped to an appropriate service and associated provider. Providing access to a consolidated source of information regarding the services available and their providers (viz. Service Directory) would significantly enhance the effectiveness and efficiency of this mapping.

\section{Project Outputs}

The aim of this project is to determine the most appropriate design specifications and implementation strategy for a directory of the services (viz. Service Directory), which would be provided across the (Department). It would become an important enterprisewide information resource to support a wide range of business activities across the Department and funded service providers.

In order to achieve the above outcomes, project deliverables would include:

1. A Functional Requirements document that provides a detailed and comprehensive analysis and assessment of the demand for and possible benefits derived from a Service Directory; 
2. A comprehensive survey, analysis and assessment of any national and/or local initiatives aimed at establishing standards for a directory of service information;

3. A System Design Specifications document that would provide detailed technical specifications regarding the underlying data model and architecture that would be required of the Service Directory database in order to provide the functionality required by current and future users, as identified in the Functional Requirements document;

4. A Business Case for establishing a Service Directory in accordance with the above System Design Specifications;

5. A Project Plan for developing the proposed Service Directory; and

6. A "proof-of-concept" demonstration implementation of such a Service Directory, limited to selected services.

Although only a shortened version of the project brief, it was hoped to leave the reader with the impression that the problem is not immediately obvious. The concern driving the client's perspective, that a solution is required, is unclear, but also the thing or object that needs to be inquired about is not very clear. These comments are not intended to single out this particular project. It is the authors' experience that this is the norm at this stage of a project definition. The manager is creating the project in his mind while trying not to close down new suggestions that may re-bound the solution. Moreover, the lack of clarity is often simply a problem of making the project explicit. The writer may tacitly understand what is wanted but, when making it explicit, is not revealing all of the underlying assumptions. This is made worse by feeling required to write using management-speak such as outputs and scientific inquiry assumptions such as objectifying the project and it being an act of discovery rather than one of social construction. Moreover, there seems to be some pressure to pretend that future new projects can be forecast and thus described perfectly so that the novice consultant needs only to follow a predefined algorithm.

This particular underlying assumption is revealed by the absence of any mention of planning or coordination meetings or of any mention of learning from doing (undertaking the project).

Reading through carefully, drawing on their limited perception of the problems of information coordination in very large and diverse public organizations, the authors located on the phrase, "a consolidated source of information regarding the services available and their providers (viz. Service Directory)" as the OBJECT. What this was exactly, its definition and boundary, was not clear at this stage. Also, it was not clear what the client thought the problem was that this object would solve. Nor was it clear what the problem owners wanted done. 
The brief did make clear (in the part edited out) that the project manager was John, so he would be the problem owner and he would say at whom any project report should be targeted at (the audience).

What follows is an e-mail dialogue that attempted to clarify for the authors the object, concern, argument, and evidence required to complete the project. E-mail was used so a detailed record was available but the downside is that interaction is limited compared to face-to-face dialogue. Hopefully the gist of questioning pattern can still be appreciated.

Authors: What would you say is the ОВJECT or thing you want the (novice consultant) to study? Is it a Service Directory? Can you explain what you mean by this a bit further?

Manager: The purpose (ie outcomes) of this project is to design a Service Directory that will provide ready access to information regarding the range of...services...that are provided by the Department, its funded service providers and the private sector, as well as information regarding the providers of these services. In order for the Department to provide highquality, timely and responsive services that are tailored to meet the specific needs of clients, the Department requires ready access to this information stored within the Service Directory.

Thus, the deliverables (outputs) from this project would include:

(a) a document that details the functional requirements for the proposed Service Directory; and

(b) a document that details the System Design Specifications for the Service Directory database, which is likely to be implemented as a RDBMS.

While most of this reply is about what the directory will do, rather than what it is, it has helped identify the object under inquiry as "a Service Directory database that will provide ... information regarding the range of... services...that are provided by the Department." Having a better notion about the object, it was now possible to move on to the concern.

Authors: What is about this that CONCERNS you about the Service Directory?

Manager: Unclear as to this question, however:

The major challenge for this project is to recommend a design for the database that will provide efficient and effective retrieval of information about services and their providers. For example, a likely scenario may be that the end-user (eg staff responding to inquiry from a client) needs to recommend a service (or suite of services) that are most likely to address their client's concerns and/or needs. To perform this task, the end-users need ready access to information 
regarding what services are available that address these particular needs, how are they accessed, where are they located, what are the eligibility criteria etc. Hence, the design specifications must address these data access and retrieval demands.

This seems to have at least further clarified the object, as a servicesavailable database that would be of use to the staff members answering inquiries from client about the department's services. However, also emerging is the manager's concern about how to design this service database, collecting requirements and drafting a specification being how the design is to be determined. Interestingly, he was unclear about the question of his concerns but transferred the idea on to those who might use the database. He understood that his job was to manage the concerns of his clients, in that particular designing the database should be centered on addressing their concerns.

To help pull together the object and concern, the next question was intended to help identify the report's argument (conclusion).

Authors: In what form do you see the conclusion (ARGUMENT) of the report?

Manager: Project "products" (outputs/deliverables) would be:

(a) a document that details the Functional Requirements Specifications for the proposed Service Directory; and

(b) a document that details the System Design Specifications for the Service Directory database, which is likely to be implemented as a RDBMS.

This seems to confirm the boundary of the project with the object as the services database and the concern as its design, using his clients' concerns collected through the requirements and specification process. It is assumed the argument will be of the form, "that $\mathrm{X}$ is the best requirements and specification of the database." Next the source of the evidence to determine best needs to be clarified.

Authors: How do you expect the (consultant) to collect the supporting EVIDENCE? By talking to whom, for how long etc? Looking where?

Manager: Functional Requirements Specifications must be obtained from the end-users that will be using this database. Hence, this could include service providers themselves who provide inquiry services through helpdesk etc, as well as staff operating help-desk and/or call-centres, that are responding to inquiries from the community on behalf of the service providers.

Cheers 
This has clarified the user-stakeholders as providing at least some of the criteria to decide the best requirements and specification. It was now possible to ask for a little more information defining the database and the requirements gathering, but these would be rolling planning with expected modifications as evidence was collected.

Space does not permit continuing this inquiry process here. Nor does it permit running through the other 13 projects. We can report, however, that much the same process was found useful for both the novice consultants and the project managers to varying degrees for all projects. When the projects were completed, the authors solicited feedback from the project managers who all reported satisfaction that the novice consultant had delivered what was expected. This was in contrast to previous occasions where there had been some disagreement between the project manager and the novice consultants.

It is hoped that the illustrations are sufficient to illustrate at least that there is a requirement in project definition for some way of structuring the conversation to draw out the implied argument in a project, which includes separating the object under consideration from the perspective of the person considering the object.

\section{CONCLUSIONS}

The object of this paper is project definition. The authors are concerned that managers are not aware of the usefulness of the traditional structured dialogue method, argumentation. The argument that argumentation is useful for critiquing attempts at project definition was started by defining argument to make explicit its attributes as an inquiry method. These attributes included that it encourages social construction through structured dialogue, it provides a boundary to the problem domain, it aligns with epistemological calls to inquirers to make explicit their up-front perspectives, argument is acceptable to scientific and interpretive inquiry, and it suggests an ongoing process that can expose stakeholders' perspectives.

However, the argument method becomes particularly attractive when it is able to take advantage of perspectival thinking (Haynes 2000), that is, encourage the separation of the object under inquiry from the several possible perspectives of stakeholders on that object. Exemplars of this are Morgan's (1986) metaphors of organizations and Mitroff and Linstone's (1993) TOP perspectives. It was then suggested that the nontechnical perspectives could be drawn from managers by asking for their concerns rather than using language such as, 'What is your perspective?' This frame was then used to develop a pattern of questions that could be asked in order to help define a project. An example of the pattern of questioning that draws on the argument/perspectival approach was provided. 
It is also hoped that readers agree that the argumentative approach to critiquing project definitions warrants further investigation. It is part of a whole genre of structured human discourse (e.g., Eemeren et al. 1987; Ulrich 1983). Within that, there is considerable debate about what argument is, how it works, and whether there are better ways of structuring the discourse. For those of a scientific bent, argument uses competition to seek the truth; for the interpretivists, it is a means of seeking justification of interpretations. In both epistemologies, it is an up-front intellectual frame, contrasting with induction and emerging concepts from grounded theory. All that said, argument is also an incredibly practical inquiry methodology, used in many households, bars, and courtrooms to learn, justify and seek justice or effectiveness.

Project definition, from the first ill-conceived thought to the stakeholders' approved collective mind set, is a thinking, inquiring, understanding, justifying, and competitive exercise. This exercise is made so much harder by the need to balance the bound (scope) of the project concept, yet allow for learning both from as yet unknown sources and from action. The learning from doing literature, which includes Polanyi's (1966) tacit knowledge ideas, warns us to expect to shift our perspective on problems after we have physically attempted to solve them. This is challenging to project definition when there is considerable pressure to sign off on even innovative projects prior to the start. Requirement analysis tools are useful, but only after the stakeholders have at least attempted a collective, strategic, concept formulation. We believe that argument provides a discourse-based, boundary and purpose setting, critiquing approach that can help project definition. It is a method used at present but implicitly, and therefore sometimes incompletely.

\section{REFERENCES}

Alvesson, M., and Skoldberg, K. Reflexive Methodology. Thousand Oaks, CA: Sage, 2000.

Angell, I. O. "Systems Thinking about IS and Strategies," Journal of Information Technology (5), 1990, pp. 168-174.

Apotheloz, D., Brandt, P., and Ouiroz, G. "The Function of Negation in Argumentation," Journal of Pragmatics (19), 2993, pp. 23-39.

Arygris, C. "Actionable Knowledge," Journal of Applied Behavioral Science (32:4), 1996, pp. 390-406.

Argyris, C., and Schön D. A. Organizational Learning II. Reading, MA: Addison Wesley, 1996.

Avison, D. E., and Wood-Harper, A. T. Multiview: An Exploration in Information Systems Development. Oxford: Alfred Waller Ltd., 1990.

Baskerville, R. L., and Wood-Harper, A. T. "A Critical Perspective on Action Research as a Method for Information Systems Research," Journal of Information Technology (11), 1996, pp. 235-246.

Batiste, J. L., and Jung, J. T. "Requirements, Needs, and Priorities: A Structured Approach for Detecting MIS Project Definition, MIS Quarterly, December 1984, pp. 215-227. 
Broad, W., and Wane, N. Betrayers of the Truth. New York: Simon and Schuster, 1982.

Chalmers, A. F. What Is This Thing Called Science. St. Lucia, Queensland: University of Queensland Press, 1982.

Checkland, P. "Soft Systems Methodology: A Thirty Year Retrospective," Systems Research and Behavioral Science (17:1), 2000, pp. S11-S58.

Checkland, P. Systems Thinking, Systems Practice. Chichester: John Wiley \& Sons, 1981.

Churchman, C. W. The Design of Inquiring Systems. New York: John Wiley \& Sons, 1971.

Crosswhite, J. The Rhetoric of Reason. Madison: University of Wisconsin Press, 1996.

Darke, P., and Shanks, G. "User Viewpoint Modeling, Information Systems Journal (7), 1997, pp. 213-239.

Davidson, D. Inquiries into Truth and Interpretation. Oxford: Oxford University Press, 1984.

Davis, G. B. "Information Systems as an Academic Discipline: Explaining the Future," Journal of Information Systems Education (14:4), 1992.

East, C., and Metcalfe, M. "Rich Pictures for Identifying Concerns," Working Paper, University of South Australia, 2002.

Eemeren, F. H., Grootendorst, R., and Kruiger, T. Handbook of Argumentation Theory. Dordrecht: Foris Publications, 1987.

Fischer, F., and Forrester, F. The Argumentative Turn, Durham, NC: Duke University Press, 1993.

Fitzgerald, B. "Formalized Systems Development Methodologies," Information Systems Journal (6), 1996, pp. 3-23.

Fitzgerald, B. "Systems Development Methodologies: The Problem of Tenses," Information Technology \& People (13:3)), September 2000, pp. 174-185.

Giddens, A. The Constitution of Society. Berkeley: University of California Press, 1984.

Haynes, J. Perspectival Thinking. OneIdea Company, 2000.

Hirschheim R., Klein, H. K., and Lyytinen K. "Control, Sensemaking and Argumentation," in Proceedings of the Fifth Australian Conference on Information Systems, Melbourne, Australia, 1997.

Hospers, J. Human Conduct. New York: Harcourt Brace Jovanovich, 1982.

Jayaratna N. Understanding and Evaluating Methodologies-NIMSAD-A Systemic Framework. New York: McGraw-Hill, 1994.

Keeney R. L. "Creativity in Decision Making with Value Focused Thinking," Sloan Management Review, Summer, 1994, pp. 33-41.

Klein, H., and Myers, M. "A Set of Principles for Conducting and Evaluating Interpretive Field Studies in Information Systems," MIS Quarterly (23:1), 1999, pp. 67-93.

Kummerow, E. H. Differentiating Organizational Subcultures. Auckland, NZ: ANZAM, 2001.

Kuhn, T. S. The Structure of Scientific Revolutions. Chicago: The University of Chicago Press, 1970.

Linstone, H. Multiple Perspectives for Technology Mangers. New York: Wiley, 1999.

Mason, R. O. “A Dialectical Approach to Strategic Planning," Management Science (15), 1969, pp. B-403-B-414.

Mason, R. O., and Mitroff, I. I. Challenging Strategic Planning Assumption. New York: John Wiley \& Sons, 1981.

Metcalfe, M. "The Argumentative Methodology," IT and People (5), $2002 \mathrm{a}$.

Metcalfe, M. Business Research Through Argument. Boston: Kluwer Academic, 1995.

Metcalfe, M. "Concern Solving for ISD," in M. G. Hunter (ed), Socio-technical and Human Cognition Elements of Information Systems. Harrisburg, PA: Idea Group Publishing, 2002 (forthcoming).

Metcalfe, M., and Powell, L. "Revisiting Argument," Australian Conference on Information Systems, Brisbane, $2000 \mathrm{~b}$. 
Meyers, R. A., and Seibold, D. R. "Perspectives on Group Argument," Communications Yearbook (14), 1989, pp. 268-302.

Mitev N. Information Systems Failures. Unpublished Ph.D. thesis, London School of Economics, 2000.

Mitroff, I. "The Myth of Objectivity," Management Science (18), 1972, pp. B613-618.

Mitroff, I., and Linstone, H. The Unbounded Mind. Oxford: Oxford University Press, 1993.

Morgan G. Images of Organizations. Thousand Oaks, CA: Sage Publications, 1986.

Moynihan T. "Coping with Client Based People Problems," Information and Management (39), 2002, pp. 377-390.

Myers, M., and Avison, D. Qualitative Research in Information Systems: A Reader. Thousand Oaks, CA: Sage, 2002 (forthcoming).

Neal, R. A. "Project Definition," International Journal of Project Management (13:1), 1995, pp. 5-9.

Niederman, F., and DeSanctis, G. "The Impact of the Structured Argument Approach on Group Problem Formulation," Decision Sciences (26:4), 1995.

Perelman, C., and Olbrechts-Tyteca, L. The New Rhetoric: A Treatise on Argumentation. Notre Dame, IN: University of Notre Dame, 1969.

Pettigrew, A. M. "Success and Failure in Corporate Transformations," in R. D. Galliers and W. R. J. Baets, Information Technology and Organizational Transformation: Innovation for the 21 st Century Organization. Chichester: John Wiley \& Sons, 1998.

Polanyi, M. The Tacit Dimension. Garden City, NY: Doubleday \& Co., 1966.

Popper K. R. The Open Society and Its Enemies. Princeton, NJ: Princeton University Press, 1971.

Popper K. R. Conjectures and Refutations. London: Routledge and Keegan Paul, 1972.

Provis, C. "Interests vs Positions: A Critique of the Distinction," Negotiation Journal (12:4), 1996, pp. 305-323.

Roberts, N. "Coping with Wicked Problems," Research Conference of the International Public Management Network, Sydney, Australia, 4-6 March 2000.

Russo, N. L. "Exploring the Assumptions Underlying Information Systems Methodologies: Their Impact on Past, Present and Future ISM Research," Information Technology \& People (13:4), November, 2000.

Schön, D. The Reflective Practitioner. New York: Basic Books, 1983.

Scult, A. "Heidegger on Aristotle,"www.multimedia2.drake.edu/s/scult/h-on-a.html, June, 1999.

Settle, T. "The Rationality of Science Versus the Rationality of Magic," Philosophy of the Social Sciences, 1971, pp. 173-194.

Settle-Murphy, N., and Thorton, C. "Facilitating Your Way to Success," Information Strategy, (15:3), 1999, pp. 36-45.

Smith C. C. "Improved Project Definition," Hydrocarbon Processing, August 2000.

Sowell T. Marxism. London: Unwin. 1985.

Toulmin, S. E. The Uses of Argument. Cambridge: Cambridge University Press, 1964.

Tracey, T. J. G., and Glidden-Tracey, C. E. "Integration Theory, Research Design, Measurement and Analysis," Counseling Psychologist (27:3), 1999, pp. 299-324.

Truex D. P., Baskerville R., and Klein H. "Growing Systems in Emergent Organizations," Communications of the ACM (42:8), 1999, pp. 117-123.

Ulrich, W. Critical Heuristics of Social Planning. New York: Wiley, 1983.

Ulrich W. "The Philosophical Staircase for ISD," Journal of Information Technology Theory and Application (3:3), 2001.

Vickers, G. The Vickers Papers. London: Harper \& Row, 1984.

Von Bertalanffy, L. General System Theory: Foundations, Development, Applications. New York: George Braziller, 1968.

Walton, D. The New Dialectic. Toronto: Toronto University Press, 1998. 
Wastell, D. G. "The Fetish of Technique," Information Systems Journal (6), 1996, pp. 25-40. Weick, K. E. "Managerial Thought in the Context of Action," in W. Bennis, R. O. Mason, and I. I. Mitroff (eds.), The Executive Mind. San Francisco: Jossey Bass, 1983.

Ziegelmueller, G. W., and Dause, C. A. Argumentation: Inquiry and Advocacy. Englewood Cliffs, NJ: Prentice-Hall, 1975.

\begin{abstract}
About the Authors
Mike Metcalfe is an associate research professor at the University of South Australia, where he is thesis advisor to $20 \mathrm{Ph} . \mathrm{D}$. candidates. He holds a Ph.D. from Adelaide University, Australia (1994), and a M.Sc. in Business Planning from Salford University, UK (1981). His publications include four books and numerous refereed articles on the design of human inquiry, including information strategies, research methods, and forecasting. He has worked in the merchant navy, the army reserves, system design, lecturing, and consulting, including a term as adviser to the Deputy Premier of South Australia. His present research interests include the use of argument, systems thinking, and multiple perspectives to define problems. Mike can be reached by e-mail at mike.metcalfe@unisa.edu.au.

Maureen Lynch is program director for the Business Information Systems Co-operative program at the University of South Australia. Previously, she was employed as an academic, lecturing in information systems both in South Australia and overseas. Her research interests are in project definition and, in particular, the role of journals to aid project definition. Maureen can be reached by e-mail at Maureen.Lynch@unisa.edu.au.
\end{abstract}

